\title{
De Cambridge para o Mundo, Historicamente: Revendo a Contribuição Metodológica de Quentin Skinner
}

João Feres Júnior

"The one duty we owe to history is to rewrite it."

Oscar Wilde

\begin{abstract}
publicação recente de Linguagens do Ideário Político, uma coletâA nea de textos de J.G.A. Pocock (2003), tornou disponível pela primeira vez em língua portuguesa parte da contribuição desse autor ao debate metodológico sobre a história do pensamento político. É interessante notar que, enquanto esses textos chegam agora ao leitor brasileiro, contribuições metodológicas mais centrais à metodologia historicista, da qual Pocock esposa, ainda não foram traduzidas para o português. Refiro-me aqui, principalmente, aos trabalhos de Quentin Skinner e também a outras contribuições que procuraram, de alguma maneira, elucidar aspectos metodológicos daquela que foi posteriormente rebatizada pelo próprio Skinner de abordagem collingwoodiana ${ }^{1}$ ao estudo da história do pensamento político (Skinner, 2001). Essa lacuna se torna ainda mais significativa se considerarmos que os principais trabalhos historiográficos do autor já foram traduzidos (idem, 1996a; 1996b), e que seus escritos, assim como os de Pocock, integram os programas de cursos de história, teoria política e filosofia política por todo o país.
\end{abstract}

DADOS - Revista de Ciências Sociais, Rio de Janeiro, Vol. 48, nº3, 2005, pp. 655 a 680. 
Entre os autores que esposaram de alguma maneira a abordagem collingwoodiana, podemos identificar, além de Skinner e Pocock, Anthony Pagden, James Tully, Richard Tuck e John Dunn. Porém, dentre todos, Skinner é, sem dúvida alguma, o autor que mais se esforçou em sistematizar um projeto metodológico para a história intelectual. Começando em 1966 com "The Limits of Historical Explanations", e tomando força em 1969 com a publicação daquele que se tornaria seu texto mais polêmico e contundente sobre a matéria, "Meaning and Understanding in the History of Ideas", a cruzada metodológica de Skinner manteve-se ativa até os dias de hoje (Skinner, 2002)², seja através de suas próprias contribuições, das várias respostas que essa tem suscitado, ou mesmo das tentativas de aproximação, empreendidas por adeptos anglófonos da Begriffsgeshichte.

O esforço intelectual de Skinner no campo metodológico teve dois objetivos principais. O primeiro foi promover uma total revisão das abordagens mais influentes ao estudo da história do pensamento político, nas quais identifica problemas metodológicos batizados por ele de mitologias. O segundo objetivo que animou sua empreitada foi a proposição de um novo programa para o estudo da disciplina. Skinner parece ter tido sucesso quanto ao primeiro objetivo, pois, se não conseguiu acabar de vez com os presentismos e idealismos na prática da história do pensamento político, abriu um espaço amplo para o exercício do historicismo lingüístico dos collingwoodianos, isto é, para o estudo das "idéias em contexto" 3 . É a parte propositiva de sua contribuição, contudo, que a meu ver é problemática.

O novo programa proposto por Skinner suscitou uma ampla resposta. Alguns comentadores apontaram para suas inconsistências internas (Gunnell, 1982; Graham, 1988; Hollis, 1988), outros acusaram o autor de promover um tipo de positivismo que se mostra incapaz de refletir sobre o papel do intérprete na produção de leituras (Fermia, 1988; Keane, 1988; Minogue, 1988), outros ainda deitaram-lhe a pecha de adepto do antiquarianismo (Tarlton, 1973). O presente artigo pretende ser uma contribuição à essa literatura crítica. Contudo, dada a fartura e diversidade do material crítico produzido durante as últimas três décadas, meu esforço só terá sentido se de alguma maneira for capaz de apresentar algo que ainda não foi cotejado. Há, a meu ver, um aspecto que, apesar de não ter sido tratado de maneira significativa pela literatura crítica, é central ao programa metodológico de Skinner. Pretendo mostrar que todo o edifício da metodologia skinneriana se assenta so- 
bre um erro, qual seja, o de trabalhar com a premissa, presente em todos os seus trabalhos sobre metodologia, de que comunicação oral e comunicação textual não são significativamente diferentes, ou melhor, com a premissa de que uma teoria desenhada para a análise dos atos de fala pode ser simplesmente aplicada, sem maiores adaptações, à interpretação de textos.

Não basta, contudo, apontar para a existência dessa premissa no texto de Skinner e simplesmente declarar sua natureza equivocada. Tem-se que, de fato, indicar porque ela é errônea, o que implica mostrar que essas duas modalidades de comunicação diferem uma da outra em aspectos importantes que não foram cotejados pelo autor. Para tal, a argumentação dar-se-á através dos seguintes passos: começo com a exposição dos aspectos principais do projeto metodológico de Skinner, chamando atenção para a operação da premissa supracitada; em seguida mostro que, apesar de representar uma facção importante das críticas ao projeto do autor, a hermenêutica de inspiração gadameriana não está bem posicionada para identificar esse problema; por fim, baseado nos apontamentos de Paul Ricoeur sobre as especificidades da comunicação textual, que chamo aqui de fenomenologia do texto, exporei as diferenças cruciais em relação à comunicação oral introduzidas pelo ato da escrita. No decorrer deste exercício crítico, mostrarei que a fenomenologia do texto é um ponto de partida privilegiado para organizar algumas das críticas anteriormente feitas a Skinner, e também uma passagem para novas possibilidades metodológicas que não foram cotejadas pela abordagem collingwoodiana.

Antes de expor os problemas inerentes ao projeto metodológico de Skinner, é preciso primeiro apresentar suas linhas gerais. Na verdade, ele sofreu algumas mudanças com o passar dos anos, apesar de muitos de seus aspectos principais terem sido preservados. Já no final da década de 1960, em "Meaning and Understanding", o autor expõe brevemente seu projeto de inovação. Após dedicar grande parte desse longo artigo a uma crítica primorosa das principais correntes do mainstream da história do pensamento político, Skinner volta-se para o problema que, segundo seu modo de ver, está no cerne da questão epistemológica da disciplina: a produção de significado através do uso da linguagem. Na verdade, já é desse ponto de vista que o autor promove sua empreitada crítica, acusando uma e outra abordagem de produzirem 
interpretações equivocadas através da violação, distorção ou pura ignorância das condições em que a comunicação lingüística se dá. De acordo com Skinner, o entendimento (understanding) de uma sentença (statement) não corresponde estritamente à compreensão de seu significado (meaning), isto é, a sentença contém algo mais:

"Foi demonstrado de maneira clássica [...] por J. L. Austin que o entendimento de sentenças pressupõe a compreensão não somente do significado de um dado enunciado (utterance), mas também do que Austin chamou de força ilocuninária intencional" (Skinner, 1969:45-46).

Portanto, conclui Skinner, esse entendimento requer o conhecimento da intenção do autor ao proferir tal ato de fala. Segundo ele, a questão a respeito do que um agente pode estar fazendo ao (doing in) proferir o enunciado não concerne ao significado desse enunciado propriamente dito, mas sim à força que se coordena ao significado do enunciado, que é um aspecto essencial para o entendimento de tal ato (idem). Emprestando a terminologia de Austin, Skinner chama essa força de ilocucionária ou de conteúdo ilocucionário do ato de fala.

Qualquer pessoa com alguma leitura da teoria dos atos de fala conhece esse argumento. $\mathrm{O}$ que está sendo dito por Skinner a despeito de sua formulação não muito enxuta é que o entendimento do conteúdo comunicativo do enunciado não se restringe ao conteúdo propriamente semântico do que é dito. O que sobra, isto é, aquilo que está a mais, é exatamente a intenção dada pelo autor ao ato. Por exemplo, a frase "feche a porta" pode ser proferida com intenções diversas, de ordem, conselho, súplica, ironia etc. Portanto, tanto para o falante quanto para sua audiência, o entendimento correto dessa intenção é crucial para a compreensão correta do ato (Skinner, 1972).

Desses apontamentos acerca da maneira como a linguagem falada é entendida, Skinner salta diretamente para o problema da interpretação de textos, como se fossem as duas uma só problemática. Segundo o autor:

"Mesmo se pudéssemos decodificar o significado de uma sentença através do estudo de seu contexto social, ainda ficaríamos sem compreender a intenção de sua força ilocucionária, e, portanto, sem um entendimento real da sentença. O problema é, em suma, que uma lacuna inevitável permaneceria: mesmo se o estudo do contexto social de textos pudesse servir para explicá-los, ele não serviria como instrumento para 
entendê-los [...]. A compreensão da força, assim como a do significado, é essencial ao entendimento de textos" (1969:46).

Na passagem acima, o autor transpõe o modelo de entendimento da comunicação oral previamente delineado para o problema da interpretação de textos, esforçando-se para separar o significado convencional do texto, que é dado pelo contexto lingüístico no qual ele está inserido, da força ilocucionária proprimente dita. Uma leitura cuidadosa do texto mostra que Skinner usa os termos statement e utterance de maneira indistinta. Acontece que esses termos do vocabulário inglês não são sinônimos perfeitos. Enquanto utterance se refere primordialmente a um enunciado falado, o statement pode ser tanto falado quanto escrito. Contudo, esse não é um sinal de falta de atenção, mas sim uma evidência de sua convicção na propriedade de se aplicar a teoria dos atos de fala ao problema da interpretação textual.

Como conseqüência dessa transposição teórica, Skinner conclui que, somente dessa maneira (compreendendo os dois aspectos da comunicação), é possível entender aquilo que "o autor, ao escrever na época em que escreveu, para a audiência que ele pretendeu alcançar, poderia na prática ter a intenção de comunicar ao proferir um dado enunciado" (1969:49). Ou seja, o modelo da comunicação falada o induz a conceber a possibilidade do resgate perfeito do conteúdo comunicativo original imprimido ao texto. Ele então conclui que, "dessa maneira, o foco apropriado desse estudo é concebido como essencialmente lingüístico e sua metodologia correta, portanto, diz respeito ao resgate das intenções" (ibidem).

Em um esforço de polir os elementos básicos de sua teoria da interpretação, Skinner publicou em seguida a "Meaning and Understanding" dois artigos em que discute questões concernentes à teoria dos atos de fala (Skinner, 1971a; 1971b). No texto intitulado "On Performing and Explaining Linguistic Actions", o autor apresenta de maneira mais sistemática seus apontamentos sobre a relação entre significado e entendimento, e sobre os conteúdos, ou forças, dos atos de fala. Essa sistematização se encontra resumida nas passagens seguintes:

"O entendimento da natureza do ato ilocucionário perpetrado pelo falante ao proferir um dado ato de fala parece análogo (talvez equivalente) ao entendimento daquilo que Grice chamou de significado nãonatural - isso se construirmos esse conceito como o significado do ato do falante ao proferir um dado ato de fala. E o entendimento desse sig- 
nificado "não-natural" - isto é, a compreensão daquilo que o falante, ao proferir um dado ato de fala, pode ter querido dizer - de fato parece equivaler ao entendimento daquilo que o falante pretendia fazer ao proferir o dado ato de fala. Identificar nesse caso a natureza da força ilocucionária coordenada com o significado ordinário daquilo que foi dito equivale a entender a natureza da ação (lingüística) perpetrada pelo falante ao dizer o que disse" (Skinner, 1971b:2).

Enquanto Skinner havia afirmado previamente que a força ilocunionária de um dado ato de fala não deveria ser confundida com seu significado, agora ele parece voltar atrás ao chamar essa força, seguindo a terminologia de Grice, de significado "não-natural" - mudança terminológica que não transforma o conteúdo de sua teoria. Em um artigo imediatamente posterior a suas contribuições à filosofia da linguagem, Skinner aplica essa reelaboração terminológica ao problema da interpretação textual.

"Parece-me que o conhecimento das intenções do autor ao escrever, no sentido que tentei isolar, não é meramente relevante, mas na verdade equivalente ao conhecimento do significado3 $\left[{ }^{4}\right]$ daquilo que ele escreve. Dessa maneira, a equivalência entre as intenções ao escrever e o significado daquilo que foi escrito é estabelecida. Pois, como já indiquei, saber o que um autor quis dizer (meant) com um dado trabalho é saber quais eram suas intenções ao escrevê-lo" (Skinner, 1972:404).

Uma vez mais, Skinner trata de maneira equivalente, ou mesmo indistinta, a interpretação de textos e a compreensão dos atos de fala. É interessante notar que essa transposição agora é ainda mais arriscada do que a sugerida em "Meaning and Understanding", pois se antes Skinner igualava atos de fala a sentenças (statements), agora ele os iguala a trabalhos inteiros, algo que só contribui para nublar a compreensão de sua proposta.

Na passagem acima, Skinner conclui que aquilo que o autor intencionou ao escrever um dado trabalho, seu significado e o entendimento conferido a ele pelo intérprete, é de fato idêntico, ou, para usar as palavras do próprio autor, "equivalente". Através dessa afirmação, o autor está defendendo a primazia do autor na determinação do significado correto de seu trabalho. Conseqüentemente, ele conclui que uma interpretação válida é aquela que o próprio autor teria hipoteticamente aceito como uma descrição correta daquilo que ele quis dizer ou fez. Pois, segundo Skinner, esse critério "excluiria a possibilidade de que 
uma descrição aceitável do comportamento de um agente pudesse resistir à demonstração de que ela, de fato, dependeu do uso de critérios de descrição e classificação que não estavam disponíveis para o próprio agente" (idem,1969).

Skinner parece ter consciência de que a defesa da possibilidade do resgate total da intenção autoral e da proposição de que é isso que importa na interpretação de textos pode soar um pouco extremada para uma audiência que aprendeu a suspeitar das promessas da ciência social positivista e também conhece as críticas formuladas contra ela pela hermenêutica de Gadamer, pela teoria crítica e pelo pós-estruturalismo. Nas páginas iniciais de "Meaning and Understanding", Skinner diz que é impossível para um historiador estudar o que um autor disse sem ser influenciado por suas próprias expectativas sobre aquilo que o autor deve ter dito. Porém, no conjunto do argumento exposto no texto, esse preâmbulo tem uma função eminentemente retórica. A ele segue-se uma advertência contra os perigos de se contaminar o resgate das intenções autorais puras com nossas próprias expectativas.

Skinner por fim desiste de defender abertamente a autoridade, em última instância do autor, sobre o significado de seu texto no artigo intitulado "Some Problems in the Analysis of Political Thought and Action". Contudo, a essa aparente mea culpa se segue a defesa da noção de que o conhecimento da intenção de um autor ao escrever (in writing) o texto e o significado desse mesmo texto são equivalentes (Skinner, 1974).

Nota-se em "Some Problems" um esforço do autor de reformular aspectos de seu projeto de modo a escapar a algumas das críticas mais argutas, que naquele momento já haviam começado a circular no meio acadêmico. As palavras "utterance" e "illocutionary force" desaparecem do seu texto. Ademais, Skinner declara abertamente que sua primeira tentativa de aplicar a teoria e o método dos atos de fala foi malsucedida, sem contudo oferecer um detalhamento da natureza de seu erro. Como anotei no parágrafo acima, ele desiste da premissa da autoridade do autor sobre o significado do texto. Agora, Skinner propõe que a compreensão da intenção autoral advém do conhecimento das convenções lingüísticas que historicamente contextualizam o texto. Essas convenções "fechariam" o rol de significados que o texto pode ter tido. Skinner também descarta o princípio de que o resgate da intenção do autor deva ser o objetivo principal da interpretação, adotando a fórmula mais branda que coloca esse resgate "entre as tarefas do intérprete". 
De acordo com Skinner, em "Some Problems", a história da teoria política deveria ser escrita como uma história de ideologias, isto é, como um processo de formação e mudança ideológica.

\footnotetext{
"Essa história teria várias vantagens que se somariam ao fato de poder nos dar pela primeira vez um quadro realista de como o pensamento político em suas várias formas foi produzido no passado. Ela nos permitiria iluminar os papéis diversos desempenhados por fatores intelectuais na vida política, abrindo-nos o caminho para o estabelecimento de conexões entre o mundo da ideologia e o mundo da ação política. E isso, por sua vez, adicionaria uma dimensão a mais no estudo da história geral, que parece, no momento, faltar mesmo nas obras de seus autores mais consagrados" (idem:280).
}

Apesar do novo vocabulário e da mudança de foco, o projeto renovado de Skinner ainda preserva elementos importantes do anterior. Ademais, ele é ainda mais ambicioso. $\mathrm{O}$ autor, na verdade, não desiste da tese do resgate total do significado do texto, dado que ela continua sendo uma das tarefas do intérprete, que agora são estendidas ao estudo dos eventos não lingüísticos daquilo que Skinner chama de "história geral" $^{\prime \prime}$. O mais importante, porém, é notar que a declaração de fracasso na aplicação da teoria dos atos de fala não leva Skinner a retirá-la de sua proposta metodológica. Na verdade, a opção pela primazia das convenções lingüísticas sobre a autocompreensão do autor na determinação do significado é consonante com os fundamentos da teoria dos atos de fala. Como defende Austin, convenções sociais são condições necessárias para a compreensão exitosa do conteúdo ilocucionário de um ato de fala. Se essas convenções não existem ou são mal-interpretadas pelo falante, a comunicação falha e o "ato que se propunha fazer se torna nulo ou vazio"' ${ }^{\prime}$. Skinner parece ter chegado à conclusão de que sua tese original era difícil de sustentar, dado que se, por um lado ela postula um possível acesso às intenções do autor, por outro, ela não explicita as fontes desse conhecimento ou a maneira como ele seria produzido. Na formulação anterior, fica claro que o conteúdo locucionário (semântico) é de natureza convencional, mas não há qualquer clareza quanto às fontes do ilocunionário. Portanto, ao adotar em sua reforma o estudo da convenção como método para se conhecer também a intenção autoral, Skinner tenta se livrar da aporia inicial e transpõe de maneira ainda mais completa a teoria dos atos de fala para seu projeto de interpretação de textos. 
Skinner às vezes chama seu trabalho de hermenêutica ${ }^{7}$, termo de origem grega que reapareceu na academia alemã durante a primeira metade do século XIX, nos meios dedicados ao estudo da interpretação do texto bíblico. De tecnologia de interpretação textual, a hermenêutica ganhou importância filosófica, primeiro como método por excelência das ciências humanas, com Wilhelm Dilthey (1976), e, depois, como atributo principal da condição do homem como um ser cultural, com Martin Heidegger e Joan Stambaugh (1996) e Hans-Georg Gadamer (1995). A escolha do termo por Skinner não deixa de ser irônica dado que muitos autores se baseiam exatamente na hermenêutica filosófica para criticar seu projeto. Joseph V. Fermia, por exemplo, escreve que mesmo Dilthey, que defende a noção de que o intérprete deveria entender o autor melhor do que o autor entendeu a si próprio, por outro lado, afirma que o intérprete está preso à sua própria situação, experiência, valores e costumes. Para Fermia, toda história é "contemporânea", no sentido de que o seu fazer é ditado pelos interesses do intérprete no presente. Ele conclui dizendo que entender uma obra de acordo com as intenções de seu autor não é necessário e tampouco desejável (Fermia, 1988).

Mas a maior fonte de inspiração crítica ao projeto skinneriano vem mesmo da hermenêutica de Gadamer. Contrário à primazia do autor sobre o significado do texto, Charles Taylor argumenta a noção de que a interpretação requer uma negociação entre a linguagem do historiador e a do texto - negociação essa que pode vir a transformar a primeira. Isto é, ao entrar em contato com as linguagens do passado, o historiador é deslocado de sua situação original e, portanto, torna-se capaz de examinar a tradição contemporânea a qual pertence de um ponto de vista crítico ${ }^{8}$.

Também gadameriano, John Keane (1988) acusa Skinner de propor um modelo positivista de interpretação que há muito tempo foi "abandonado dentro dos círculos mais sofisticados da teoria da interpretação". Como Fermia, ele afirma que a situação histórica do intérprete é condição de possibilidade e ponto de partida necessário ao processo hermenêutico. Ao contrário daquele autor, contudo, Keane argumenta que a interpretação não requer a submissão do passado aos interesses do intérprete. Seguindo Gadamer, Keane afirma que, no ato interpretativo, o intérprete entra em conversação com o texto de maneira que a distin- 
ção entre sujeito do conhecimento e objeto é parcialmente apagada. A interpretação é um embate entre a alteridade espacial e temporal do texto e o horizonte do mundo (world horizon) do autor: uma fusão de horizontes (Horizontverschmelzung) que deve ser resolvida na linguagem do presente. Contrariando as pretensões de resgate total de Skinner, Keane conclui que "cada época deve, portanto, entender um texto transmitido a sua própria maneira" (1988:216).

A teoria da interpretação de Paul Ricoeur também é inspirada na filosofia de Gadamer ${ }^{7}$. Contudo, há diferenças entre as duas que são de grande relevância para a reflexão que conduzo aqui. O projeto hermenêutico de Gadamer é, na verdade, muito mais ambicioso que o de Ricoeur. Baseando-se em Heidegger, Gadamer escreve que "a interpretação não é uma atividade humana específica mas a estrutura básica de nossa experiência de vida" (1984:58). Diferentemente de autores que conferiam à hermenêutica um papel mais restrito - como técnica de interpretação textual para (Schleiermacher) ou método das ciências humanas (Dilthey) - Gadamer a amplia até abarcar as esferas histórica, lingüística e estética da vida humana. O autor, porém, reconhece que a "lingualidade" (Sprachlichkeit) da experiência humana media tanto as experiências históricas quanto as estéticas. Seu interesse, portanto, é pela linguagem enquanto parole e não como langue, isto é, linguagem como ação vivida em oposição aos sistemas lingüísticos. Para Gadamer (1975), parole é o dado definidor da experiência humana e, portanto, o núcleo do esforço hermenêutico.

Ricoeur, por seu lado, tem uma compreensão mais restrita da hermenêutica. Ele argumenta que a tentativa de Gadamer de promover a compreensão hermenêutica de uma modalidade de conhecimento a um modo do ser e da relação com os seres e com a existência, na verdade, tornou a hermenêutica incapaz de tratar o problema epistemológico das ciências sociais. Isto é, do ponto de vista epistemológico, a hermenêutica de Gadamer não oferece uma solução alternativa à concepção ingênua proposta por Dilthey de se encarnar o autor, mas somente um desvio para questões de ordem ontológica que nunca se traduzem em ganhos de ordem metodológica. Seguindo essa senda crítica, Ricoeur redefine a hermenêutica como "a teoria das operações do entendimento em sua relação com a interpretação de textos" (1981:43); ao invés de estendê-la às três esferas da experiência humana enumeradas por Gadamer, esse autor propõe uma teoria da interpretação que começa pela experiência da leitura. 
O interesse de Gadamer pela ação lingüística (parole) leva-o a privilegiar o diálogo como um modelo de interação lingüística. Conseqüentemente, ele dá menor importância para o problema do "ser para o texto" (Sein zum Texte). Ricoeur, por sua vez, observa que nossas experiências estéticas e históricas são mediadas primordialmente, não pela linguagem falada, mas por "signos, trabalhos e textos nos quais as heranças culturais estão inscritas, e se oferecem para serem decifradas" (1981:9). Portanto, a "qualidade de ser inscrito" (Schriftlichkeit) torna-se em sua teoria mais importante que a lingualidade.

O interesse pela linguagem como ação e, conseqüentemente, a pouca atenção dada aos problemas introduzidos pela inscrição são duas características comuns às teorias interpretativas de Gadamer e Skinner ${ }^{8}$. Como pretendo mostrar na seção seguinte, essa característica similar em ambas as teorias permite-nos usar a fenomenologia do texto de Ricoeur, originalmente elaborada como crítica a Gadamer, para identificarmos os erros embutidos na proposta metodológica de Skinner.

Minha intenção aqui não é esposar o todo do projeto hermenêutico de Ricoeur, que para o autor consiste em uma nova epistemologia para as ciências sociais. Pretendo, sim, fazer um uso instrumental de sua contribuição e apropriar dela somente aquilo que possa contribuir para uma crítica eficaz da metodologia collingwoodiana. Ademais, dado que a fenomenologia pode ser vista como um positivismo radical para Husserl ela é o único positivismo de fato (Gadamer, 1984) - seu confronto com a proposta de Skinner oferece uma oportunidade interessante de se jogar um positivismo contra outro.

É fato que a hermenêutica, particularmente a de inspiração gadameriana, pode ser usada para identificar problemas no projeto collingwoodiano, como o fizeram os críticos acima comentados. Contudo, penso que, ao invés de expor as contradições e imperfeições internas à metodologia de Skinner, esse tipo de crítica a contrasta com um esquema filosófico que lhe é totalmente estranho. Gadamer escreve dentro de uma tradição intelectual a qual investiga o problema da relação entre sujeito e objeto do conhecimento há mais de dois séculos. Sua reflexão acerca da hermenêutica dialoga com as teorias e conceitos da filosofia da consciência - para usar um termo de Habermas -, da hermenêutica de Dilthey e Schleiermacher, da fenomenologia de Husserl e da filosofia do ser de Heidegger. Essa tradição é tão diversa daquelas que inspiram a teoria de Skinner - o empiricismo inglês e a filosofia da lingua- 
gem - que pouco podemos esperar da conversação entre elas. Essa conversação hipotética se complica ainda mais quando consideramos a aversão de Gadamer à idéia de que a hermenêutica possa ser aprisionada pelo método (Gadamer, 1975; 1984) - a proposta de Skinner não seria uma exceção.

III

Não seria difícil contrastar o apego radical de Skinner à intencionalidade do autor com teorias que declaram a morte do autor e da autonomia do texto, como o estruturalismo de Roland Barthes e Stephen Heath (1977) ou o projeto arqueológico de Michel Foucault (1972). Contudo, o empreendimento torna-se mais produtivo se pudermos escolher um autor cujo ponto de partida e fundamentos teóricos não sejam totalmente estranhos a Skinner. Paul Ricoeur parece ser talhado para a empreitada.

Assim como Skinner, Ricoeur também se debruça - mas não com exclusividade - sobre o problema da interpretação de textos históricos. Ambos os autores consideram a comunicação como ação social e a tomam como uma forma de texto. Ademais, a Ricoeur também interessa a questão da relação entre interpretação e intenção do autor. Diferentemente deSkinner, contudo, esse autor leva o problema do texto muito a sério.

Ricoeur dá-se conta de que a comunicação entre o intérprete e o ato intencional do autor em escrever é mediada pelo texto - um meio de comunicação que impõe limitações específicas ao conteúdo daquilo que é de fato comunicado. O autor começa sua reflexão sobre o assunto com uma questão que Skinner nunca cotejou em seus artigos sobre metodologia: há problemas específicos, relativos à interpretação de textos, os quais podem ser atribuídos ao fato de o intérprete lidar com textos e não com linguagem falada? (Ricoeur, 1981).

A resposta para essa questão requer um exame delicado das particularidades que diferenciam a comunicação falada da linguagem escrita. Ricoeur começa a explorar a matéria com a introdução do conceito de discurso. Segundo ele, discurso é um evento de linguagem e, como tal, deve ser entendido em oposição aos sistemas ou códigos de linguagem. Enquanto esses últimos são coleções de unidades léxicas e fonológicas construídas por lingüistas, discurso é o produto vivo da ativi- 
dade humana que tem a sentença como unidade. Para Ricoeur, "é a lingüística da sentença que baseia a teoria da fala como evento" (1981:74).

Não podemos deixar de notar a semelhança entre as concepções de sentença oral esposadas por Ricoeur e Austin. Apesar da diferença de vocabulário, ambos os autores defendem que o entendimento não pode ser reduzido à mera compreensão dos conteúdos semântico e sintático da sentença. Isto é, para eles o discurso é uma forma de ação social - um evento, nas palavras do autor francês.

Ao chamar o discurso de evento, Ricouer pretende sublinhar o fato de que esse não pode ser reduzido a uma mera construção ideal. Como todos os eventos, discurso deve ser estudado de acordo com suas características fenomenológicas, ou seja, da maneira como ele se dá no mundo. $\mathrm{O}$ autor identifica quatro características fundamentais. A primeira corresponde à sujeição do discurso ao fluxo temporal. O tempo do discurso é o presente, pois o ato de enunciá-lo ainda não existe no passado, e seu efeito sonoro rapidamente dissipa-se depois que a sentença é enunciada, isto é, ele não se estende em direção ao futuro. Segunda, o discurso é auto-referenciado, no sentido de que ele é prenhe de referências explícitas e implícitas a seu autor, o falante. Terceira, ele versa sobre algo que está fora dos limites do código da língua, referindo-se ao mundo que é por ele expressado, descrito e/ou avaliado. E quarta, o discurso é um ato de comunicação e, portanto, tem não somente um sujeito humano, mas uma audiência-objeto também humana (Ricoeur, 1981).

Essa rápida exposição das características do discurso segundo Ricoeur revela ainda outros pontos em comum com Austin. Como o ato de fala, o discurso está atado à intencionalidade subjetiva do autor e não pode ser reduzido ao seu conteúdo estritamente lingüístico. Por fim, mesmo que indiretamente, sugere-se a importância que as convenções sociais partilhadas entre falante e audiência têm para o entendimento do discurso.

Uma vez que as características fenomenológicas do discurso falado são enumeradas, as especificidades introduzidas pelo ato da escrita podem ser examinadas. Primeiro, como argumenta Ricoeur, a escrita modifica a temporalidade do discurso. O discurso, enquanto evento existe somente no presente. Porém, o ato da escrita produz uma fixação do discurso que é capaz de sobreviver ao evento na forma de uma seqüência coerente de caracteres alfabéticos. A escrita é uma técnica ma- 
terial originalmente criada para facilitar a memorização. Contudo, essa técnica mnemônica não preserva o discurso em sua totalidade original. Segundo Ricoeur, a escrita não preserva o discurso como evento; esta fixa somente o "dito" do discurso. A questão que resta esclarecer, portanto, é como o "dito" do discurso difere do discurso como evento vivido.

Ricoeur empresta as categorias formuladas por Austin para explicar essa diferença ${ }^{9}$. Segundo ele, o ato locucionário do enunciado é aquilo que é preservado mais integralmente pela inscrição. Esse conteúdo é fixado através de formas léxicas e sintáticas e permanece igual a si mesmo, no sentido de que, uma vez escrita, uma sentença pode sempre ser identificada consigo mesma. A força ilocunionária, por sua vez, é apenas parcialmente apreendida pela inscrição. Enquanto o uso de convenções gramaticais e léxicas pode permitir a identificação e reidentificação da intenção comunicativa do autor, os elementos mímicos, de gesto e de entonação, característicos da linguagem falada, perdem-se na escrita. Por fim, o ato perlocucionário, por se basear ainda mais fortemente nos aspectos emocionais e afetivos da comunicação oral, também não é em grande parte capturado pela escrita. Em suma, a comunicação é afetada de maneiras diferentes pela escrita: seu conteúdo locucionário é preservado, enquanto o ilocucionário e o perlocucionário são parcialmente retidos. Ricoeur concorda que:

“[...] é necessário entender por significado do ato de fala (o noema do dito), não apenas a sentença, no sentido estreito do ato proposicional [ato locucionário], mas também a força ilocunionária e mesmo a ação perlocucionária, na medida em que esses três aspectos do ato de fala são codificados, organizados dentro de paradigmas, e onde, consequentemente, eles podem ser identificados e reidentificados como tendo o mesmo significado" (1981:200).

Se parássemos nesse ponto da análise, pensaríamos que as conclusões de Ricoeur quanto ao entendimento de textos são de fato muito próximas às de Skinner, particularmente da última versão de sua proposta metodológica apresentada em "Some Problems". Em relação à objeção de que a perda dos significados associados aos elementos não lingüísticos da comunicação acarretaria uma compreensão muito incompleta da força ilocucionária, Skinner poderia corretamente contra-argumentar que o autor tem consciência de que aspectos como entonação, gestos e mímicas não podem ser expressos através dos caracteres do texto, concluindo o fato de, na comunicação textual, a escolha das con- 
venções lingüísticas feita pelo autor ser a única fonte de entendimento dessa força.

Contudo, a aparência de concordância entre esses dois autores desaparece quando nos damos conta de que, na verdade, eles não estão tratando do mesmo problema. Ricoeur examina as diferenças entre fala e escrita de maneira progressiva. Quando se debruça sobre a primeira característica particular introduzida pela inscrição, usando categorias austinianas, Ricoeur está considerando uma temporalidade somente de curto prazo, isto é, aquele necessário para que a fala se desvaneça e a escrita sobreviva. Portanto, nesse contexto, ambos, intérprete e escritor, são contemporâneos. Essa contemporaneidade é a condição para que o ato preposicional e as convenções do ilocunionário sejam prontamente "identificadas e reidentificadas" pelos leitores. Em outras palavras, até esse ponto da análise, a questão de se interpretar textos escritos em um passado distante, que é, afinal de contas, o tema do projeto de Skinner, ainda não foi cotejado. Como veremos, o exame subseqüente das implicações da escrita sobre as outras três características do discurso abordará o problema da grande distância temporal entre o ato de escrever e a interpretação, com conseqüências drásticas para a possibilidade de resgate total do significado.

Para Ricoeur, a segunda característica do discurso também é afetada pela inscrição. O discurso é prenhe de referências ao sujeito falante, seu autor. A referência do discurso ao sujeito é dada pela imediatez da situação de fala, em que a audiência reconhece o autor na pessoa do falante, e também suas intenções naquilo que é dito. Portanto, entender o que o "falante quer dizer" é o mesmo que entender "o que o discurso quer dizer". A escrita, porém, destrói a equivalência imediata entre intenção autoral e significado do discurso. O discurso escrito não perde o autor, mas a relação entre as intenções desse e o significado do texto é "distendida e complicada". Segundo Ricoeur,

"[...] a carreira do texto escapa o horizonte finito da vida do autor. O que o texto diz agora importa mais do que aquilo que autor quis dizer. Toda exegese adota procedimentos dentro de um círculo de significados que já quebrou suas amarras com a psicologia do autor" (1981:201).

Para ele, a presença física e psicológica do autor é a garantia do reconhecimento de sua "possessão" do significado daquilo que é dito ${ }^{10}$. Dado que o texto não conta com a imediatez da presença do autor, seu significado é acessível apenas através da interpretação - um tipo de in- 
terpretação que não vislumbra resgatar a intenção autoral original que foi perdida para o texto junto com a presença do autor.

A falta de atenção de Skinner ao caráter mediativo do texto leva-o a falar de autores como se sua presença fosse de alguma maneira acessível ao intérprete e a interpretação nos desse a oportunidade de presenciar o enunciar de seus atos de fala e também reconhecesse esses atos como produtos da ação intencional de um sujeito específico. Contudo, somos forçados a perguntar, do ponto de vista do intérprete, quem é esse autor-sujeito? Quem são Maquiavel, Hobbes ou Francisco Vitória, senão coleções de material escrito? Como tal, eles apresentam-se para nós, intérpretes do presente, sempre através do mesmo meio, o texto. Alguns comentadores acusam os collingwoodianos de alimentarem a “ilusão da presença do autor" (Harlan, 1989:586). Essa crítica é correta na medida em que, contrário ao que Skinner sugere, não parece haver maneira possível de se eliminar a mediação textual no ofício do intérprete da história do pensamento político e, assim, garantir seu acesso à pura intenção autoral.

Ricoeur afirma que o discurso sempre representa algo que é exterior ao código lingüístico - sua terceira característica fenomênica. Enquanto evento, o discurso é cercado por uma situação que é compartilhada pelas partes envolvidas - falante e audiência - fazendo referência aos aspectos dessa situação através de expressões dêiticas e sinais físicos de referência. Em outras palavras, a referência é uma característica ostensiva da comunicação oral. A inscrição, por seu turno, abre uma vala entre a referência do autor e de seu público. No caso de textos antigos, a situação original do autor não está mais à disposição do leitor. Isso leva Ricoeur a concluir que "da mesma maneira em que o texto livra seu significado da tutelagem da intenção mental, ele livra sua referência dos limites da referência ostensiva" (1981:201).

Skinner sabe da importância do entendimento mútuo da referência para o sucesso da comunicação oral. Baseado na distinção entre sentido e referência, elaborada por Frege, Skinner afirma que a referência não é parte do significado de uma palavra, mas o "critério de sua aplicação correta", a coisas particulares, ações e situações. Para Skinner, a referência é uma ponte entre "a palavra e o mundo"11. Ou seja, a concepção de referência abraçada por Skinner não é diferente da de Ricoeur. Contudo, o problema da interpretação de textos do passado é novamente ignorado quando Skinner transforma essa teoria da situa- 
ção de fala no centro de um projeto metodológico para o estudo da história intelectual, pois ele está de fato deixando de ver que a inscrição também transforma o mundo do autor em palavras (escritas). Para o intérprete, não há nenhum acesso imediato possível ao mundo do passado que não seja mediado pelo próprio texto ou por textos contemporâneos. O texto é necessariamente a única fonte disponível à interpretação, e as palavras contidas nele somente se referem a mais palavras no próprio texto ou em algum outro. A interpretação é presa do círculo da textualidade, na qual a distinção entre sentido e referência se torna obsoleta.

Na verdade, Skinner parece acreditar na possibilidade de se resgatar também as referências ostensivas da situação original do autor. Isso poderia ser feito através da coleta de informações sobre a biografia do autor e o contexto histórico geral de sua vida. Entretanto, Skinner não nos revela como poderíamos ter certeza do significado que as palavras escritas por um jesuíta do século XVI, por exemplo, tiveram para ele e para aqueles que lhe foram contemporâneos. Como nota Gordon J. Schochet (1974), há uma contradição básica no projeto metodológico proposto pelo autor, pois ele pretende manter a linguagem do passado imune à poluição lingüística do presente e, ao mesmo tempo, fazer isso usando instrumentos conceituais derivados da tradição filosófica e crítica do século XX. Há somente duas soluções possíveis para esse dilema. Uma seria considerar o instrumental analítico de Skinner algo de fato transistórico e, portanto, útil para interpretação de textos produzidos em qualquer período. Isso, contudo, estaria em desacordo com sua tese de que não há teorias transistóricas. A segunda solução corresponderia a aceitar o caráter historicamente contingente do instrumental analítico. Mas isso corresponderia a aceitação da interferência necessária entre o instrumental e o objeto da análise - algo que poria em xeque a idéia de resgate total (Schochet, 1974).

$\mathrm{O}$ tipo de resgate imaginado por Skinner requer a transferência do intérprete para o mundo do autor - uma missão impossível simplesmente porque aquele mundo não existe mais enquanto experiência vivida, mas somente como texto. Na verdade, todas as fontes textuais de um dado período apresentam o mesmo problema ao intérprete: os textos que constituem o contexto não são menos problemáticos que o texto principal que se constitui enquanto objeto de análise ${ }^{12}$. Não quero aqui assumir uma posição de total pessimismo em relação à possibilidade de se extrair algum entendimento do passado. Pelo contrário, devo le- 
var em consideração a importância das fontes textuais primárias nesse entendimento, mas, de maneira complementar, tenho também que estar ciente de que as noções contemporâneas de historicidade e contexto histórico não advêm exclusivamente da interpretação direta de fontes primárias, mas também da recepção dessas pelas gerações que sucederam ao texto. Isto é, há de fato uma teia complexa de mediações textuais que condicionam nosso entendimento presente do contexto de um dado período histórico, e, portanto, condicionam também nosso entendimento do texto em contexto.

Mesmo supondo que a possibilidade de um intérprete poder entender um mundo do passado em seus próprios termos, esse entendimento ainda teria que ter validade hoje, no mundo do intérprete e, portanto, em uma linguagem do presente. Em outras palavras, à viagem ao passado deve-se seguir uma viagem de volta ao presente. Essa necessidade coloca em pauta o problema dos jogos de linguagem dos quais o intérprete é partidário (ou presa). Skinner demonstra grande sensibilidade em relação ao contexto lingüístico que cerca seu objeto de estudo, mas nem sempre a mesma disposição para integrar a sua análise os jogos de linguagem nos quais ele Skinner, está inserido. Sua falta de engajamento com o presente levou alguns comentadores a acusá-lo de conservadorismo e antiquarismo (Tarlton, 1973; Fermia, 1988; Taylor, 1988) - a primeira pecha é certamente exagerada, enquanto a segunda talvez tenha algum fundamento.

Por fim, voltando a Ricoeur, a quarta característica do discurso diz respeito à sua natureza dialógica: o discurso é sempre direcionado a uma audiência. A inscrição também tem conseqüências para esse aspecto da comunicação que não podem ser desprezadas. O texto é escrito, na maioria das vezes, para uma audiência que lhe é contemporânea; contudo, ele sobrevive não somente a seu autor e situação, mas também à sua audiência. Ao contrário do evento discursivo, que é restrito à platéia de ouvintes, o texto escrito está aberto a todos que sabem ler.

"A co-presença dos sujeitos em um diálogo deixa de ser o modelo para todo entendimento. A relação escrever-ler deixa de ser um caso particular da relação falar-escutar. Mas, ao mesmo tempo, o discurso é revelado como discurso na universalidade de seu alcance. Ao escapar [através da inscrição] o caráter momentâneo do evento, as limitações da vida do autor e a estreiteza da referência ostensiva, o discurso escapa os limites de estar 'cara a cara'. Ele não tem mais uma audiência visível. O 
leitor desconhecido e invisível se torna o alvo privilegiado do discurso" (Ricoeur, 1981:203).

A quarta conseqüência fenomenológica introduzida pelo ato da escrita aponta para um aspecto interessante da história do pensamento político que tem sido ignorado pelos autores da abordagem collingwoodiana: o estudo da recepção. Ao sobreviver à presença autoral, ao seu mundo e à sua audiência, os textos abrem-se para as novas gerações de leitores e, portanto, para novas interpretações. Essa independência relativa do texto permite que o estudo do pensamento político se enriqueça com novas possibilidades, entre elas uma ênfase maior no aspecto diacrônico da análise que permite a condução da narrativa histórica até o presente ${ }^{13}$.

Um entusiasta do enfoque collingwoodiano, David Hollinger (1989) rejeita as noções de que o texto adquire relativa autonomia semântica em relação à intenção do autor e de que os contextos não podem ser completamente resgatados argumentando que elas são importadas da teoria literária e, portanto, inadequadas à prática contemporânea e à condição hermenêutica do praticante de história intelectual. De maneira similar, Donald Kelley escreve que a "falácia da intencionalidade" é uma noção que deveria ser restrita ao estudo de textos literários, e que o estudo da recepção é inadequado ao ofício da história intelectual, pois ele é primordialmente dirigido à análise de atributos estéticos do texto, que, por sua vez, são marginais ao significado histórico central que eles carregam. Kelley vai ainda mais longe ao afirmar que o estudo da recepção objetiva somente um "enriquecimento do significado", o que redunda, de fato, na criação de novos significados. Portanto, essa ferramenta metodológica não deve ser empregada sem "qualificações" ao estudo de fontes históricas e documentais. O autor conclui que a premissa da intenção autoral é inevitável - uma ficção necessária, no mínimo - para as "histórias disciplinares", como, por exemplo, a história da ciência ou a história do pensamento político (a disciplina dos collingwoodianos par excellence) (Kelley, 1990).

Devemos, contudo, duvidar dos argumentos apresentados por esses adeptos da abordagem collingwoodiana, uma vez que o estudo da fenomenologia do texto mostra que a autoria relativa do texto em relação à intenção autoral original e seu contexto é uma conseqüência inevitável da inscrição e, portanto, não tem relação com o estilo mais ou menos literário desse mesmo texto. Em relação às origens da teoria da re- 
cepção (Rezeptionslisthetik), deveríamos ser gratos aos teóricos literários que chegaram a um refinamento metodológico tão produtivo em uma época em que os historiadores do pensamento político estavam ainda falando da "Grande Corrente do Ser" (The Great Chain of Being) e outras concepções idealistas que os próprios collingwoodianos veementemente deploram. Ademais, a atitude de qualificar como irrelevante as contribuições da teoria literária é um tanto arrogante e imprudente, dado que, entre outras coisas, esses mesmos teóricos têm acolhido os artigos de "historiadores disciplinares" como Quentin Skinner em suas próprias publicações acadêmicas ${ }^{14}$.

Ao contrário do que Hollinger (1989:611) pensa, o estudo da recepção pode constituir o centro da "condição hermenêutica do praticante da história intelectual", como é o caso da Begriffsgeschichte alemã, que é, pelo menos naquele país, uma "prática corrente" há cinco décadas. Mas as coisas estão mudando, mesmo nos meios acadêmicos de fala inglesa. O contato recente entre collingwoodianos e intelectuais ligados a Begriffgeschichte está fazendo circular na academia anglófona algumas das contribuições disciplinares germânicas. O esforço crucial de Melvin Richter (1990; 1995; 2001) em promover esse encontro, tanto através de seus escritos sobre metodologia quanto de seus trabalhos substantivos (Richter, 1997; 1999; 2000), tem demonstrado, entre outras coisas, o quanto o estudo da recepção pode também se tornar uma "prática corrente" na academia de fala inglesa, e por extrapolação, em outros meios acadêmicos ainda presos aos rigores do historicismo.

\section{IV}

O uso que fizemos da fenomenologia do texto de Ricoeur tem a vantagem de possibilitar uma crítica mais produtiva do projeto metodológico de Skinner. A exposição das diferenças entre comunicação verbal e escrita serve não somente para identificar um erro capital em Skinner, mas também para apontar para outras possibilidades metodológicas, como a valorização do estudo da recepção dos textos. Essas diferenças nos mostram que é exatamente porque estudamos textos que não podemos sonhar com o resgate total de seus significados, incluindo aí a intenção autoral. As conseqüências dessa constatação põem a abordagem collingwoodiana em xeque, pois, uma vez que a autoridade do autor e de seu contexto sobre a interpretação correta é desbancada, a necessidade de se justificar uma dada interpretação retorna ao intérprete, que terá que lidar com ela na linguagem do presente, ou melhor, em 
uma de suas linguagens. Contudo, é exatamente no presente que a política existe como experiência vivida e comunicação. Seja através de estratégias de conflito ou de entendimento racional, as linguagens políticas do presente são continuamente empregadas na reconstrução do passado e na projeção do futuro. Por conseqüência, uma disciplina que se propõe a interpretar o pensamento político não pode evitar o debate político do presente. Em suma, desistir do sonho do resgate total significa assumir a politização da atividade interpretativa. Será que os collingwoodianos estariam prontos para essa guinada?

(Recebido para publicação em outubro de 2004)

(Versão definitiva em junho de 2005)

\section{NOTAS}

1. O nome homenageia o filósofo britânico R. G. Collingwood. A alcunha original dessa abordagem é "Escola de Cambridge", que faz referência à instituição inglesa na qual ela se originou e onde trabalharam ou estudaram muitos de seus adeptos.

2. Para frustração de seus interlocutores, o tão esperado livro de Skinner sobre metodologia, recentemente publicado, é apenas uma coletânea de textos já publicados anteriormente pelo autor.

3. Título de uma coleção da qual é editor.

4. No mesmo texto, Skinner já havia definido previamente significado3 como aquele que corresponde àquilo que "o autor quer dizer (means) com aquilo que ele diz (says) em seu trabalho". Ou seja, esse significado diz respeito à força ilocucionária do ato. Note-se mais uma vez a mistura de termos relativos à fala com aqueles próprios da escrita.

5. O novo interesse manifesto do autor por ideologias leva Skinner a concentrar sua atenção sobre os esforços do autor em usar, adaptar e transformar vocabulários e teorias convencionais (jogos de linguagem) com o objetivo de justificar práticas sociais e comportamentos inovadores. Coerentemente, o interesse de Skinner pelos usos instrumentais da linguagem levam-no a revalorizar técnicas retóricas - uma démarche posta em prática em seu mais recente trabalho sobre a filosofia política de Thomas Hobbes (Skinner, 1996b).

6. Para Austin, essas convenções constituem o que ele chama de primeira condição (A.1) para o sucesso (felicity) de um ato de fala: “Deve existir um procedimento convencional aceito que tenha um determinado efeito convencional e que implique a enunciação de certas palavras por certas pessoas em circunstâncias estabelecidas" (ver Austin, 1962). 


\section{João Feres Júnior}

7. Ver Skinner (1975-1976:209-232).

8. Ver Taylor (1988). Maiores detalhes sobre as afinidades entre Taylor e Gadamer no tocante à hermenêutica e à filosofia das ciências sociais encontram-se em Gadamer (1975) e Taylor (1971). Taylor também usa da hermenêutica gadameriana - particularmente a noção de fusão de horizontes - para tentar dar uma resposta ao problema do reconhecimento de minorias em democracias modernas. Ver, ainda, Taylor (1992).

9. Não é meu objetivo aqui explicar em detalhes os aspectos comuns e destoantes da teoria de cada autor. Tal tarefa é levada a cabo pelo próprio autor em Ricoeur (1981).

10. Apesar de similares na importância que dão à parole, as teorias de Gadamer e Skinner diferem em muitos aspectos. Por exemplo, como já sugerido em minha análise dos críticos gadamerianos, Gadamer rejeita a idéia da possibilidade do resgate total do significado, algo que ele identifica na proposição de Dilthey de se colocar no lugar do autor (Ricoeur, 1981).

11. Nas palavras do autor "O ato da fala, de acordo com Austin, é constituído por uma hierarquia de atos subordinados que são distribuídos em três níveis: (1) o nível do ato locucionário ou proposicional, o ato da fala, (2) o nível do ato ilocunionário ou força ilocunionária, aquilo que fazemos ao falar (in saying), e (3) o nível do ato perlocucionário, aquilo que fazemos por falar (by saying)" (Ricoeur, 1981).

12. Ao contrário de Ricoeur, Gadamer defende que o significado e o dito nunca podem ser equivalentes. O falante não pode ter total controle sobre o significado do dito porque esse é necessariamente estruturado pela linguagem, que, por seu turno, não pertence à consciência individual do falante mas à coletividade.

13. "Word and world" no jogo de palavras em inglês. Ver Skinner (1979).

14. Reinhart Koselleck (1996) identifica a importância do estudo da recepção dos conceitos na produção de uma narrativa diacrônica, em oposição ao historicismo radical dos collingwoodianos. Em um primeiro momento, Skinner aferrou-se a sua posição historicista para defender publicamente a impossibilidade de uma história conceitual, argumentando que um conceito tem uma existência única em uma obra de um determinado autor - ver Richter e Lehmann (1996) ou Skinner (1998). Recentemente, contudo, o autor parece ter revisto sua posição anterior, passando a definir sua atividade acadêmica, e a de seus colegas de Cambridge, como uma forma de história conceitual, mas tomando o cuidado para resguardar o foco no uso de conceitos na argumentação, ou seja, "naquilo que é feito com eles" (Skinner, 2005).

15. É irônico notar que um autor que cita Michel Foucault generosamente, como Kelly, possa defender a intenção autoral como uma "ficção inevitável" para o estudo de "histórias disciplinares" como as histórias da ciência e do pensamento político. Ora, não seria o próprio Foucault um crítico acerbo da idéia de intencionalidade autoral como fonte de significado para o entendimento do texto. Foucault aponta para a intertextualidade, idéia que pode ser interpretada como uma forma de recepção. Mas Kelly parece fazer vistas grossas a essa questão. 
De Cambridge para o Mundo, Historicamente: Revendo a Contribuição...

\section{REFERÊNCIAS BIBLIOGRÁFICAS}

AUSTIN, J. L. (1962), How to do Things with Words. Cambridge, Harvard University Press.

BARTHES, Roland e HEATH, Stephen. (1977), Image, Music, Text. New York, Hill and Wang.

DILTHEY, Wilhelm. (1976), Selected Writings. Cambridge, New York, Cambridge University Press.

FERMIA, Joseph V. (1988), "Historicist Critique of 'Revisionist' Methods", in J. Tully (org.), Meaning and Context: Quentin Skinner and his Critics. Cambridge, Polity.

FOUCAULT, Michel. (1972), The Archaeology of Knowledge. New York, Pantheon Books.

GADAMER, Hans-Georg. (1975), "Hermeneutics and the Social Sciences". Cultural Hermeneutics, vol. 2, pp. 307-316.

(1984), “The Hermeneutics of Suspicion", in G. Shapiro e A. Sica (orgs.), Hermeneutics; Questions and Prospects. Amherst, The University of Massachusetts Press.

(1995), Truth and Method. New York, Continuum.

GRAHAM, Keith. (1988), "How do Illocutionary Descriptions Explain?", in J. Tully (org.), Meaning and Context: Quentin Skinner and his Critics. Cambridge, Polity.

GUNNELL, John G. (1982), "Interpretation and the History of Political Theory". The American Political Science Review, vol. 76, no 2, pp. 317-327.

HARLAN, David. (1989), "Intellectual History and the Return of Literature". American Historical Review, no 94, pp.581-698.

HEIDEGGER, Martin e STAMBAUGH, Joan. (1996), Being and Time: A Translation of Sein und Zeit, Suny Series in Contemporany Continental Philosophy. Albany, New York, State University of New York Press.

HOLLINGER, David A. (1989), “The Return of the Prodigal: The Persistence of Historical Knowing". American Historical Review, vol. 94, no 3, pp. 610-621.

HOLLIS, Martin. (1988), "Say it with Flowers", in J. Tully (org.), Meaning and Context: Quentin Skinner and his Critics. Cambridge, Polity.

KEANE, John. (1988), "More Theses on the Philosophy of History", in J. Tully (org.), Meaning and Context: Quentin Skinner and his Critics. Cambridge, Polity.

KELLEY, Donald R. (1990), "What is Happening to the History of Ideas?". Journal of the History of Ideas, vol. 51, no 1, pp. 3-25.

KOSELLECK, Reinhart. (1996), “A Response to Comments on the Geschichtliche Grundbegriffe", in H. Lehmann e M. Richter (orgs.), The Meaning of Historical Terms and Concepts: New Studies on Begriffgeschichte. Washington, D.C., German Historical Institute.

MINOGUE, Kenneth. (1988), "Method in Intellectual History: Quentin Skinner's Foundations", in J. Tully (org.), Meaning and Context: Quentin Skinner and his Critics. Cambridge, Polity.

POCOCK, J. G. A. (2003), Linguagens do Ideário Político. São Paulo, Edusp. 


\section{João Feres Júnior}

RICHTER, Melvin. (1990), "Reconstructing the History of Political Languages: Pocock, Skinner, and the Geschichtliche Grundbegriffe". History and Theory, vol. 29, no 1, pp. 38-70.

. (1995), The History of Political and Social Concepts: A Critical Introduction. New York, Oxford, Oxford University Press.

. (1997), "Europe and the Other in Eighteenth-Century Thought". Politisches Denken, vol. Jahrbuch, pp. 25-47.

. (1999), "The Concept of Despotism and 'l'Abus de Mots'". International Meeting of the History of Concepts Group, Saint-Cloud e Paris.

. (2000), "The Vast Tribe of Ideas". Archiv für Begriffsgeschichte, vol. Band 4, pp. 199-219.

. (2001), “A German Version of the 'Linguistic Turn': Reinhart Koselleck and the History of Political and Social Concepts", in D. Castiglione e I. Hampsher-Monk (orgs.), The History of Political Thought in National Context. Cambridge, Cambridge Universtiy Press.

e LEHMANN, Hartmut (orgs.). (1996), The Meaning of Historical Terms and Concepts: New Studies on Begriffgeschichte. Washington, D.C, German Historical Institute.

RICOEUR, Paul. (1981), Hermeneutics and the Human Sciences. Paris, Cambridge University Press/Editions de la Maison des Sciences de L'Homme.

SCHOCHET, Gordon J. (1974), “Quentin Skinner's Method". Political Theory, vol. 2, no 3 , pp. 261-276.

SKINNER, Quentin. (1969), "Meaning and Understanding in the History of Ideas". History and Theory, vol. 8, no 1, pp. 3-53.

(1971a), "Conventions and the Understanding of Speech Acts". Philosophical Quarterly, vol. 20, no 79, pp. 118-138.

. (1971b), “On Performing and Explaining Linguistic Actions". Philosophical Quarterly, vol. 21, no 82 , pp. 1-21.

. (1972), “Motives, Intentions and the Interpretation of Texts". New Literary History, vol. 3, pp. 393-408.

. (1974), "Some Problems in the Analysis of Political Thought and Action". Political Theory, vol. 2, Symposium on Quentin Skinner, pp. 277-303.

(1975-1976), "Hermeneutics and the Role of History". New Literary History, no 7, pp. 209-232.

. (1979), "The Idea of Cultural Lexicon". Essays in Criticism, vol. 29, pp. 205-224.

. (1996a), As Fundações do Pensamento Político Moderno. São Paulo, Companhia das Letras.

. (1996b), Razão e Retórica na Filosofia de Hobbes. São Paulo/Cambridge, UNESP/ University Press.

(1998), “Comments to Kari Palonen's 'Two Perspectives on Conceptual Change: Temporal and Rhetorical'", in Conceptual Changes in European Political Cultures: A 
De Cambridge para o Mundo, Historicamente: Revendo a Contribuição...

Planning Meeting for Co-operation between Scholars and Research Projects. London, The Finnish Institute.

. (2001), "The Rise of, Challenge to and Prospects for a Collingwoodian Approach to the History of Political Thought", in D. Castiglione e I. Hampsher-Monk (orgs.), The History of Political Thought in National Context. Cambridge, Cambridge Universtiy Press.

. (2002), Visions of Politics: Regarding Method. Cambridge, Cambridge University Press, vol. 1.

. (2005), “On Intellectual History and the History of Books". Contributions to the History of Concepts, vol. 1, no 1, pp. 29-36.

TARLTON, Charles D. (1973), “Historicity, Meaning, and Revisionism in the Study of Political Thought". History and Theory, vol. 12, no 3, pp. 307-328.

TAYLOR, Charles. (1971), "Interpretation and the Sciences of Man". The Review of Metaphysics, vol. 25, no 1 , pp. 3-51.

. (1988), "The Hermeneutics of Conflict", in J. Tully (org.), Meaning and Context: Quentin Skinner and his Critics. Princeton, Princeton University Press.

. (1992), "The Politics of Recognition", in C. Taylor e A. Gutmann (orgs.), Multiculturalism: Examining the Politics of Recognition. Princeton, N.J., Princeton University Press. 


\section{ABSTRACT \\ From Cambridge to the World, Historically: Reviewing the Methodological Contribution of Quentin Skinner}

The article identifies a central problem in the methodological proposal of Quentin Skinner for studying the history of political thought: the equivalence assumed by the author between oral and written communications. This leads him to adopt the theory of speech acts as the backbone for his methodological project. Use of the treatment given by Paul Ricoeur to the phenomenology of writing imposes differences between these two types of communications and thereby highlights the improprieties generated by Skinner's assumed equivalence. The article discusses why the critical approach towards this English author's methodology is more productive and systematic than many of the critiques aimed at him, including those inspired by the thinking of Hans-Georg Gadamer.

Key words: Quentin Skinner; history of political thought; methodology; Paul Ricoeur; interpretation

\section{RÉSUMÉ}

De Cambridge vers le Monde: Une Révision Historique de la Contribution Méthodologique de Quentin Skinner

Dans cet article, on souligne un problème central de l'approche méthodologique de Quentin Skinner concernant l'étude de l'histoire de la pensée politique: l'équivalence adoptée par l'auteur entre la communication orale et la communication écrite. Ce qui l'amène à faire de la théorie des actes de la parole l'axe de son projet méthodologique. Si l'on suit l'approche que Paul Ricoeur entreprend dans la phénoménologie de l'écrit, les différences entre ces deux types de communication s'imposent et, par conséquent, les impropriétés provoquées par l'équivalence adoptée par Skinner. On voit pourquoi l'approche critique à la méthodologie de l'auteur anglais est plus productive et systématique que la plupart des critiques qu'on lui a adressées, y compris celles inspirées de la pensée de Hans-Georg Gadamer.

Mots-clé: Quentin Skinner; histoire de la pensée politique; méthodologie; Paul Ricoeur; interprétation 